\title{
The first lidar observations of the nighttime sodium layer at low latitudes Gadanki $\left(13.5^{\circ} \mathrm{N}, \mathbf{7 9 . 2}^{\circ} \mathrm{E}\right)$, India
}

\author{
Y. Bhavani Kumar ${ }^{1}$, P. Vishnu Prasanth ${ }^{2}$, D. Narayana Rao' ${ }^{1}$, M. Sundara Murthy ${ }^{2}$, and M. Krishnaiah² \\ ${ }^{1}$ National Atmospheric Research Laboratory (NARL), P.B No 123, Tirupati 517 502, India \\ ${ }^{2}$ S.V.University, Tirupati-517 502, India
}

(Received October 26, 2006; Revised March 27, 2007; Accepted April 18, 2007; Online published June 27, 2007)

\begin{abstract}
We report on the first lidar observations of the nighttime mesospheric sodium layer from Gadanki $\left(13.5^{\circ} \mathrm{N}\right.$, $\left.79.2^{\circ} \mathrm{E}\right)$ site in India. The lidar measurements of upper atmospheric sodium made on 6 nights between the 10 and 16 January 2005 are presented in this paper. The Gadanki lidar uses a Nd:YAG pumped dye laser, tuned to the sodium D2 line $(589.0 \mathrm{~nm})$, as a transmitter. Using the system, sodium number density profiles have been obtained with a vertical resolution of $300 \mathrm{~m}$, a time sampling of $120 \mathrm{~s}$. During the initial six nights of observation, the peak sodium concentration is found at a height of $95 \mathrm{~km}$, and the top side scale height is usually about $2 \mathrm{~km}$. On three occasions, a secondary peak was observed at heights between 87 and $92 \mathrm{~km}$. Measurements at Gadanki site indicate that the mean sodium abundances appear to decrease after sunset and increase before sunrise. The average nocturnal columnar abundances were in the range $2-8.9 \times 10^{9} \mathrm{~cm}^{-2}$. The nightly mean centroid heights range between 92.9 and $95.2 \mathrm{~km}$ and the rms widths vary between 4.3 and $4.9 \mathrm{~km}$. On some nights, wave like structures in the sodium layer were observed with wavelength of about $3 \mathrm{~km}$ and downward phase velocities of about $1 \mathrm{~km} / \mathrm{hr}$. Four sporadic layers were observed during the initial $54 \mathrm{~h}$ of observation. The formation and decay of an intense sporadic sodium layer was observed on the night of 11 January 2005. The layer was found to develop between 93 and $90 \mathrm{~km}$ altitude and appear between 0230 and $0430 \mathrm{LT}$.
\end{abstract}

Key words: Resonance lidar, mesospheric sodium, sporadic sodium, mesospheric chemistry, gravity waves, sodium layer.

\section{Introduction}

It is well known that metallic sodium atoms exist in the neutral state in the upper part of the atmosphere (Slipher, 1929). Ablation of meteorites and comet dusts is believed to be the dominant source for the formation of sodium $(\mathrm{Na})$ and other metal layers in the mesosphere (Bills and Gardner, 1990; Clemesha et al., 1992; Alpers et al., 1993). The mesospheric $\mathrm{Na}$ layer generally appears in the altitude range of 80 to $110 \mathrm{~km}$ with a peak close to the mesopause where the Na number density is of the order of $10^{3}$ to $10^{4} \mathrm{~cm}^{-3}$ (Richter et al., 1981).

Since the mesospheric region is difficult to measure, being too low for satellites and too high for balloons and rocket flights are too infrequent, most studies rely on remote-sensing techniques. Over the past three decades, resonance lidar systems have been used to study most of the alkaline metals and dynamics of the mesopause region. The metal layers are useful for remote sensing as they can be excited at specific wavelengths to emit resonance fluorescence. For sodium the resonant wavelength is $589 \mathrm{~nm}$, bright orange in color, which matches the frequency of $\mathrm{Na}$ atomic transition from the ground state to the first-excited state. The resonance scatter occurs when the absorbed radiation is re-emitted by the $\mathrm{Na}$ atoms. The resonance scat-

Copyright (c) The Society of Geomagnetism and Earth, Planetary and Space Sciences (SGEPSS); The Seismological Society of Japan; The Volcanological Society of Japan; The Geodetic Society of Japan; The Japanese Society for Planetary Sciences; TERRAPUB tering is one of the most efficient scattering processes in the atmosphere. It is noted that the Rayleigh backscatter crosssection at $589 \mathrm{~nm}$ wavelength is about $3 \times 10^{-31} \mathrm{~m}^{2}$ (Nicolet, 1984), while the Na-resonance cross-section of the $\mathrm{D}_{2}$ line is about $10^{-15}-10^{-16} \mathrm{~m}^{2}$ (Fricke and von Zahn, 1985). This shows that the Na cross-section is about 15-16 orders of magnitude larger than the Rayleigh or molecular crosssection. Because of this reason, the mesospheric sodium has become the most frequently studied metallic component of the Earth's atmosphere.

Resonance lidar observations of the atmospheric sodium layer have been made by numerous groups at different locations. These studies show that the mesospheric sodium layer is subject to seasonal and shorter term variations, which differ significantly from location to location (Kwon et al., 1988; Clemesha et al., 1992; Kane et al., 1993; Clemesha, 1995; Nagasawa and Abo, 1995; Clemesha et al., 1999; Kane et al., 2001; Yi et al., 2002). The sodium layer is also an excellent tracer of the atmospheric wave motion. Perturbations generated by atmospheric tides and gravity waves have been detected by various workers (Batista et al., 1985; Gardner and Shelton, 1985; Gardner and Voelz, 1987; States and Gardner, 1999).

Much of the information about the mesospheric atomic sodium layer has been obtained from lidar measurements around the globe. However, the measurements in the tropical region are relatively sparse in comparison to those available at mid and high latitudes. Though there are some lidar 
Table 1. Main specifications of sodium lidar.

\begin{tabular}{|c|c|}
\hline \multicolumn{2}{|r|}{ Transmitter } \\
\hline \multicolumn{2}{|r|}{ Pump Laser } \\
\hline \multicolumn{2}{|c|}{ Continuum, USA make Power Lite model 8020} \\
\hline Repetition rate & $20 \mathrm{~Hz}$ \\
\hline Energy (per pulse) & $200 \mathrm{~mJ} \max$ \\
\hline Laser beam size & $8 \mathrm{~mm}$ \\
\hline Beam divergence & $0.5 \mathrm{mrad}$ \\
\hline Pulse width & $6 \mathrm{~ns}$ \\
\hline Line width & $1 \mathrm{~cm}^{-1}$ \\
\hline \multicolumn{2}{|r|}{ Dye Laser } \\
\hline \multicolumn{2}{|c|}{ Continuum, USA make Jaguar Narrow scan model D90DMA } \\
\hline Tunable range & $330-740 \mathrm{~nm}$ \\
\hline Tuning mechanism & Dual Grating \\
\hline Dye used & Sulfo Rhodamine B (Kiton Red) \\
\hline Energy (per pulse) & $25 \mathrm{~mJ}$ (normal) \\
\hline Conversion efficiency & 20 percent maximum \\
\hline Grating resolution & 2400 lines $/ \mathrm{mm}$ \\
\hline Precision & $1 \mathrm{pm}$ \\
\hline Divergence & Set to $1.0 \mathrm{mrad}$ \\
\hline Line width & $0.05 \mathrm{~cm}^{-1}$ or 2 picometer \\
\hline Stability & $0.05 \mathrm{~cm}^{-1}{ }^{\circ} \mathrm{C}^{-1}$ hours $^{-1}$ \\
\hline External beam expander & $10 \mathrm{X}$ \\
\hline (CVI, USA) & \\
\hline Divergence & $100 \mu \mathrm{rad}$ \\
\hline (After beam expander) & \\
\hline \multicolumn{2}{|r|}{ Receiver } \\
\hline Telescope diameter & $750 \mathrm{~mm}$, Newtonian type \\
\hline Field of View & $1.0 \mathrm{mrad}$ \\
\hline IF filter $\mathrm{CW}$ & $589.0 \mathrm{~nm}$ \\
\hline IF filter FWHM & $1.0 \mathrm{~nm}$ \\
\hline Peak transmission & 60 percent \\
\hline PMT & 12 dynode, low dark current ( $1 \mathrm{nA})$, not peltier cooled type \\
\hline PMT & R3234 - 01, Head-on type, Hamamatsu, Japan make \\
\hline Quantum efficiency & 8 percent \\
\hline Gain of PMT & $2.5 \times 10^{7}$ units \\
\hline \multicolumn{2}{|r|}{ Data acquisition system } \\
\hline Type & Single photon counting \\
\hline Model & EG and G Ortec, MCS-plus \\
\hline Maximum counting rate & $100 \mathrm{MHz}$ \\
\hline Bin width & $2 \mu \mathrm{s}$ \\
\hline Number of bins per pulse & 1024 \\
\hline
\end{tabular}

observations of the mesospheric sodium that have been reported from a few low latitude stations such as Mauna Kea, Hawaii $\left(20^{\circ} \mathrm{N}\right)$ (Kwon et al., 1988) and Arecibo, Puerto Rico $\left(18^{\circ} \mathrm{N}\right)$ (Beatty et al., 1989), Kototabang, Indonesia $\left(0.2^{\circ} \mathrm{S}\right)$ (Shibata et al., 2006), however, there no measurements at other lower latitudes. Another important feature of the sodium layer is the event of sporadic sodium, occurrence of sharp sodium densities in short time, whose formation mechanism is still not understood. However, the recent report by Clemesha et al. (1998) show that the occurrence rate of sporadic $\mathrm{Na}$ layers at a southern hemisphere low latitude site is quite different compared to the northern hemisphere low latitude location (Kwon et al., 1988). Thus, the measurements of mesospheric sodium at the least probed low latitude sites are important and valuable to understand the latitudinal behavior and dynamics of atmospheric sodium layer.

Recently a resonant-scatter lidar system has been setup at the National Atmospheric Research Laboratory (NARL), Gadanki $\left(13.5^{\circ} \mathrm{N}, 79.2^{\circ} \mathrm{E}\right.$; dip $12.5^{\circ} \mathrm{N}, 6.3^{\circ}$ magnetic latitude), to study the aeronomy of the mesopause region over this tropical low-latitude site on regular basis. Using the lidar system, we have observed $\mathrm{Na}$ layer at altitudes between 80 and $105 \mathrm{~km}$ during January 2005 for the first time over the Indian sub-continent and also observed sporadic formation of thin dense layers of sodium during late night hours. In this paper, we present the preliminary observations made during January 2005. 


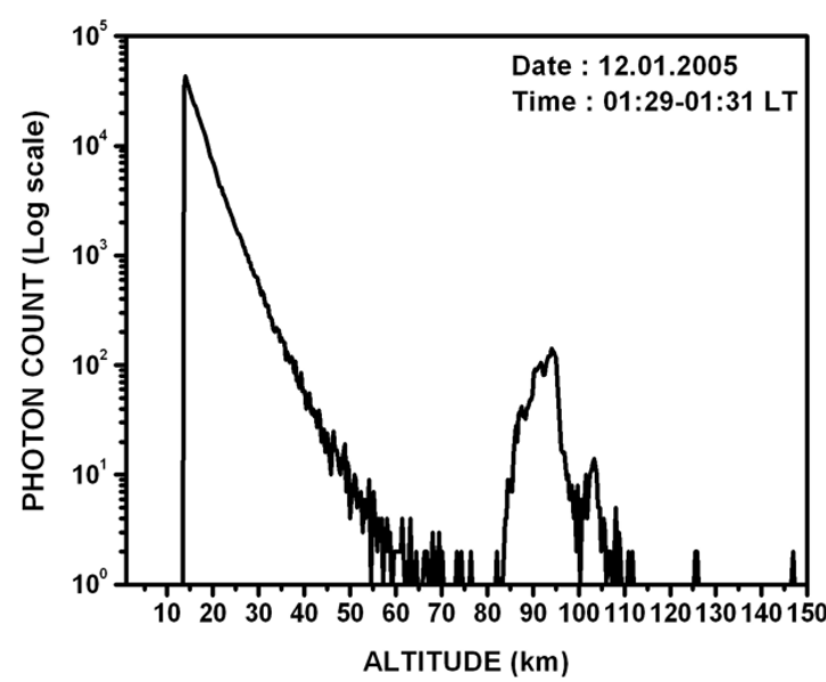

Fig. 1. Photon count profile obtained by integrating the laser returns from 2400 shots.

\section{Equipment setup}

A state-of-the art Rayleigh and Mie backscattering lidars (Bhavani Kumar et al., 2000, 2001, 2006) were set up at Gadanki $\left(13.5^{\circ} \mathrm{N}, 79.2^{\circ} \mathrm{E}\right)$ in 1998 under the Indo-Japanese collaboration programme. Recently the lidar system was augmented with the capability of probing the mesospheric sodium. The broadband Na lidar system at Gadanki was setup in a mono-static configuration. The power-aperture product of the lidar system was approximately $0.35 \mathrm{~W}$ $\mathrm{m}^{2}$. The detailed specifications of lidar system are given in Table 1 .

The transmitter consists of a tunable pulsed dye laser pumped by a frequency-doubled Nd:YAG-laser. The pulsed dye laser is tuned to the $\mathrm{D}_{2}$ resonant absorption line of $\mathrm{Na}$ at a wavelength near $589 \mathrm{~nm}$. The dye laser employs a dual grating system that is controlled by a computer and which enables a rapid selection of transmitted wavelength. The line width of laser is about two picometer. The dye laser is pumped with $200 \mathrm{~mJ}$ at $532 \mathrm{~nm}$ to get an output pulse energy of $30 \mathrm{~mJ}$ at $589 \mathrm{~nm}$. The dye laser uses Kiton Red as laser medium. The laser beam is expanded and transmitted into the atmosphere using a steering mirror. The receiving system uses a $750 \mathrm{~mm}$ Newtonian telescope with field optics and an interference filter. We employed photomultiplier tube (PMT) for photon detection. The output pulses of the PMT are amplified by a broadband amplifier and then fed into a PC based photon counting multichannel scalar (MCS). The MCS counts the pulses in successive time bins. Each time bin is set to $2 \mu \mathrm{s}$, corresponding to a vertical resolution of $300 \mathrm{~m}$. The photon counts are accumulated for 2400 shots that corresponding to a time resolution of $120 \mathrm{~s}$. A typical photon profile is shown in Fig. 1.

The resonant scattering from the Na layer is clearly seen between 80 and $100 \mathrm{~km}$. The strong photon counts at 30$60 \mathrm{~km}$ heights are essentially due to the Rayleigh-scattering from air molecules. A sudden fall in signal counts below 12 $\mathrm{km}$ was due to the application of electronic gating to PMT. The observed nonzero count rate at $60-80 \mathrm{~km}$ and above $110 \mathrm{~km}$ altitude is caused by background noise which in-

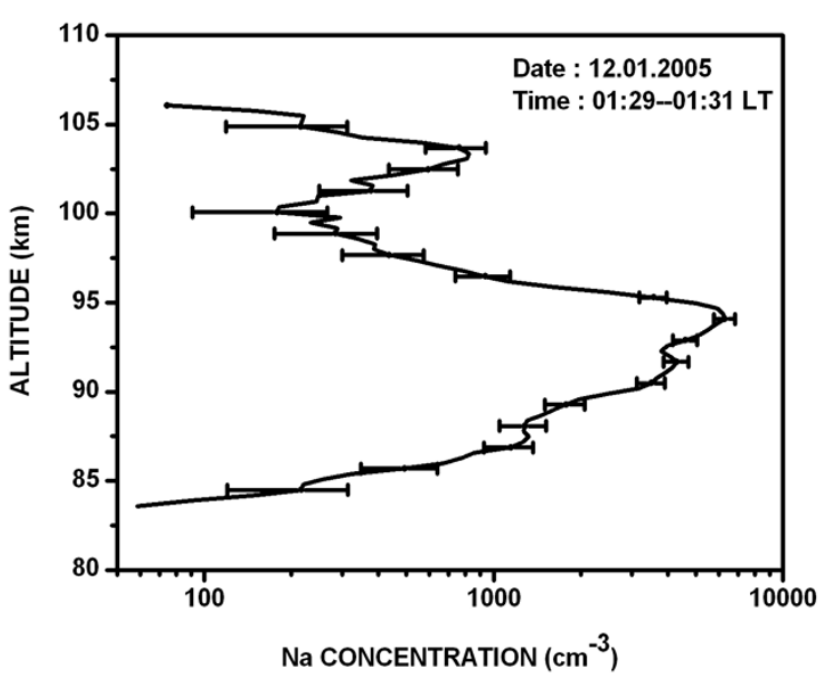

Fig. 2. Height profile of Na number density derived from the photon count profile shown in Fig. 1. The horizontal bars represent statistical error in the retrieved $\mathrm{Na}$ number density. The error bars shown are mentioned for the selected measurement points.

cludes any light sources other than the emitter light such as airglow emission, starlight, detector dark counts. It may be mentioned here that the background signal returns much above Na layer whose count level was stable and constant over the integration period is utilized in the Na density retrieval. The Na number density profiles are determined with standard computational technique given by Gardner (1989). The computational method involves the processing of photon count data for background noise correction and range normalization. The normalization altitude is usually taken above the background aerosol layer, which means above $30-35 \mathrm{~km}$ altitude. From the processed data and by using reference temperature and pressure for January from standard atmosphere model (CIRA 86), we calculated the absolute $\mathrm{Na}$ density profiles. However, the presence of sodium layer at mesospheric height causes the differential extinction to the laser beam transmission. Hence, a differential extinction correction is required for the retrieved $\mathrm{Na}$ column densities (Fricke and von Zahn, 1985; Simonich and Clemesha, 1983).

Figure 2 shows the retrieved $\mathrm{Na}$ number density profile with the differential extinction correction. It has been obtained from the photon count profile shown in Fig. 1. The $\mathrm{Na}$ density profiles are obtained with a vertical resolution of $300 \mathrm{~m}$ and a time sampling of $120 \mathrm{~s}$. The statistical error in the retrieved $\mathrm{Na}$ number density is shown in Fig. 2 as horizontal bars at selected altitudes over the Na number density profile. The detailed system and method of the mesospheric Na number density computation and the statistical error from the NARL sodium lidar is given elsewhere by Bhavani Kumar et al. (2007).

\section{Results and Discussion}

The resonance lidar measurements of mesospheric sodium were made at Gadanki on 6 days between the 10 and 16 January 2005. During most of the measurement, period sky conditions were clear. The time periods over which the lidar was operated are shown in Table 2. 
Table 2. Timing details of Na layer measurements at Gadanki site during January, 2005.

\begin{tabular}{cccc}
\hline Date & Start time & End time & Total duration (hrs) \\
\hline 10 January 2005 & 22.21 & 02.27 & 04.06 \\
11 January 2005 & 18.47 & 05.51 & 11.04 \\
12 January 2005 & 19.03 & 05.54 & 10.51 \\
13 January 2005 & 19.03 & 06.00 & 10.57 \\
15 January 2005 & 21.15 & 05.53 & 08.38 \\
16 January 2005 & 19.57 & 05.55 & 10.58 \\
\hline
\end{tabular}

Parameters such as profile structure, layer properties, wave parameters and formation characteristics of sporadic thin dense layers generally characterize the mesospheric $\mathrm{Na}$ layer. The profile structure of mesospheric Na layer shows the distribution of sodium in the layer, top and bottom scale heights and the altitude of peak sodium. The layer parameters such as column abundance $\left(\mathrm{C}_{o}\right)$, centroid height $\left(\mathrm{z}_{o}\right)$ and rms width $\left(\sigma_{o}\right)$ provide the structure of the mesospheric sodium layer. Wave parameters inform the details of propagating wave period, velocity and wave number. Characteristics of sporadic formation of thin dense layers of sodium include their time of occurrence, duration, thickness, altitude and maximum density.

\subsection{Profile structure}

Figure 3 shows the average sodium profile for the entire measurement period. The mean sodium profile starts to appear around $80 \mathrm{~km}$. During the measurement period, only once, we see sodium lower than this but not below 75 $\mathrm{km}$. The layer reaches its peak close to $95 \mathrm{~km}$ and then falls to near zero value around $105 \mathrm{~km}$. The peak density value is around $4000 \mathrm{~cm}^{-3}$. The measured profile structure of the sodium layer is very similar to that observed at other locations (Kirchhoff and Clemesha, 1973; Clemesha et al., 1998). Above the peak, the vertical gradient in sodium number density was seen with a smaller scale height, which is about $2 \mathrm{~km}$. Photo-ionisation has been suggested as loss mechanism which produce a steep topside by removing atoms as they diffuse upwards (Hanson and Donaldson, 1967). Above $90 \mathrm{~km}$, the Na layer is controlled by ionic rather than neutral chemistry (Plane, 1991). On the bottom side of the layer, the sodium density falls off less rapidly. However, the sodium profile measured on 10 January 2005 shows an unusually small-scale height, with a steep gradient, on the underside of the sodium number density between the heights of 83 and $85 \mathrm{~km}$. A rapid decrease in the atomic $\mathrm{Na}$ number density on the underside of the layer is mainly caused by the corresponding decrease in atomic $\mathrm{H}$ and $\mathrm{O}$ (Clemesha et al., 1995). With respect to the bottom side of the sodium layer, a number of loss mechanisms for the removal of sodium have been suggested in the literature: these include oxidation, mainly by $\mathrm{O}_{2}$ and $\mathrm{O}_{3}$, the formation of cluster ions, and attachment of aerosols particles (Richter and Sechrist, 1979; Hunten, 1981; Kirchoff et al., 1981; Granier et al., 1985; Plane, 1991; Clemesha et al., 1995). The top vertical gradient in sodium density is quite similar to the observations reported by Kirchhoff and Clemesha (1973) at $23^{\circ} \mathrm{S}$ and Clemesha et al. (1998) at $2^{\circ} \mathrm{S}$. The centroid height for the mean profile shown in Fig. 3 is

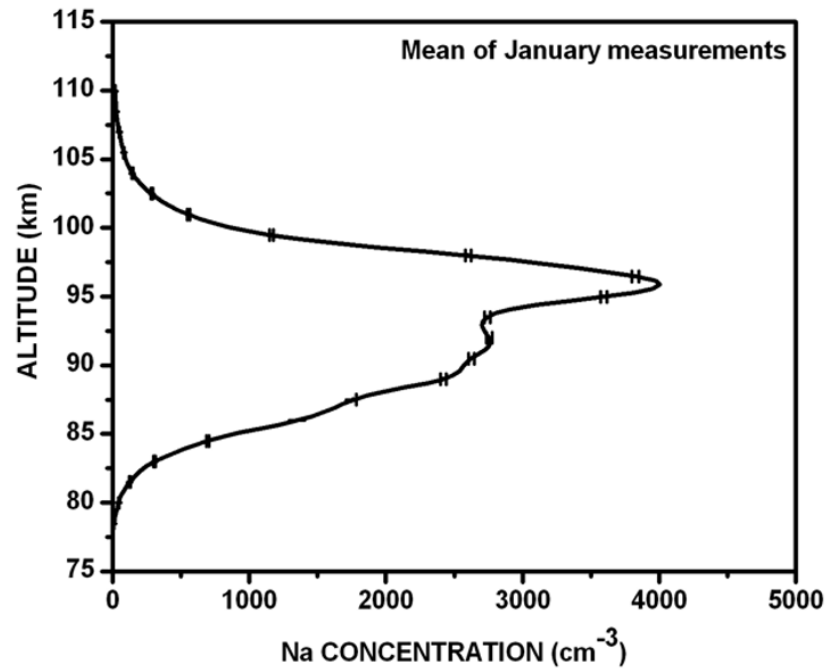

Fig. 3. Mean vertical distribution of the mesospheric sodium measured at Gadanki during January 2005.

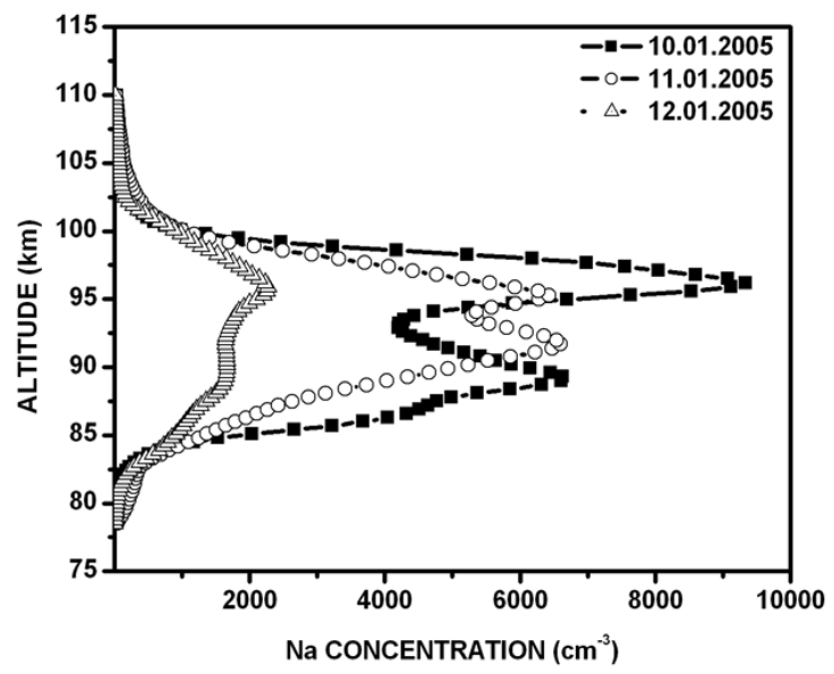

Fig. 4. Mean Na profiles for 10, 11, and 12 January 2005 showing double peaked structure.

$93.0 \mathrm{~km}$. This is $900 \mathrm{~m}$ above the Sao Jose $\left(23^{\circ} \mathrm{S}\right)$ annual mean and $500 \mathrm{~m}$ higher to the measured mean at Alcantara $\left(2^{\circ} \mathrm{S}\right)$ (Clemesha et al., 1998).

In Fig. 4, we show the average profiles for three consecutive nights 10, 11, 12 January 2006. These profiles show a double peaked structure with primary layer peak at about $95 \mathrm{~km}$. The secondary peak in sodium number density was observed at heights between 87 and $92 \mathrm{~km}$. The mesosphere is a region of complex photochemical and dynamic interaction. The distribution of sodium strongly depends on background distribution of the minor species, such as $\mathrm{O}_{3}, \mathrm{O}$, and $\mathrm{H}$ (Clemesha et al., 1995; Xu et al., 2003). It is also affected by vertical transport and diffusion. The lower peak perhaps might be due to the contribution of the mesospheric photochemistry. Sometimes horizontal and vertical motion fields in the $70-90 \mathrm{~km}$ region might transport atomic oxygen downward producing an increase in the abundance of this constituent in this region. The lifetime of atomic oxygen is of the order of a day 


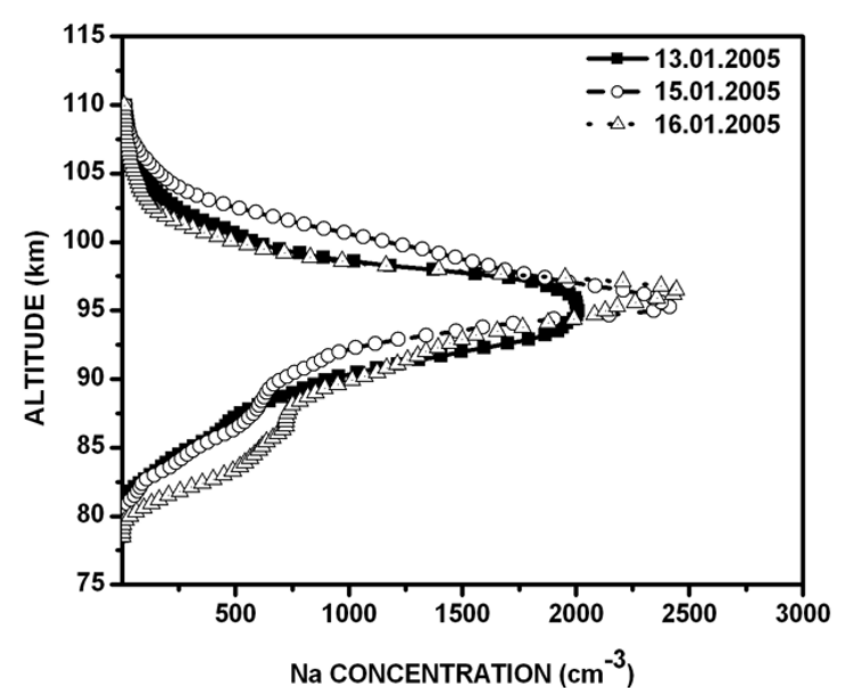

Fig. 5. Mean Na profiles for 13, 15, and 16 January 2005 showing single layer structure.

or more in this region so that vertical motions as small as 1-10 $\mathrm{cm} \mathrm{s}^{-1}$ would be expected to be an important factor in determining the atomic oxygen abundance (Geisler and Dickinson, 1967). Since atomic oxygen is involved in reducing the sodium compounds to atomic sodium, this might be expected to cause a corresponding increase in the atomic Na number density (Clemesha et al., 1995). Thus, the secondary peak of atomic sodium observed could possibly be due to an abrupt increase in atomic oxygen abundance in this region. However, observations and numerical model simulations also indicate that sodium profiles often experience time-dependent large perturbations that are thought to be due to transport associated with gravity waves (Gardner and Voelz, 1987; Clemesha et al., 2001; Xu and Smith, 2003).

We observed a considerable night-to-night variability in the structure of measured mean sodium profiles. Figure 5 shows the average profiles for three subsequent nights 13 , 15, 16 January 2006. The profiles show a single peak at $95 \mathrm{~km}$, with a gradual decrease in number density above and below this height. The peak sodium number densities for these profiles appear between 2000 and $2500 \mathrm{~cm}^{-3}$. The profiles show a variation in the peak position of the layer. These profiles were obtained during the time intervals 1903-0600, 2115-0553 and 1957-0555 LT on 13, 15 and 16 January, respectively. It may be mentioned here that the atmospheric waves can cause distortions on the mean sodium layer structure (Gardner and Voelz, 1987; Clemesha et al., 2001). It appears that the structural changes in these profiles may be partly due to perturbations by atmospheric waves such as tides and gravity waves.

\subsection{Na layer properties}

The structure of the mesospheric Na layer can be characterized by the column abundance $\left(\mathrm{C}_{o}\right)$, Centroid height $\left(\mathrm{z}_{o}\right)$, and rms layer width $\left(\sigma_{o}\right)$. The layer parameters are calculated from the different moments of the mesospheric $\mathrm{Na}$ layer as given by Gardner et al. (1986). Figure 6 shows the average column abundance, centroid position and width of the Na layer for the entire observational period. Figure 6(a)
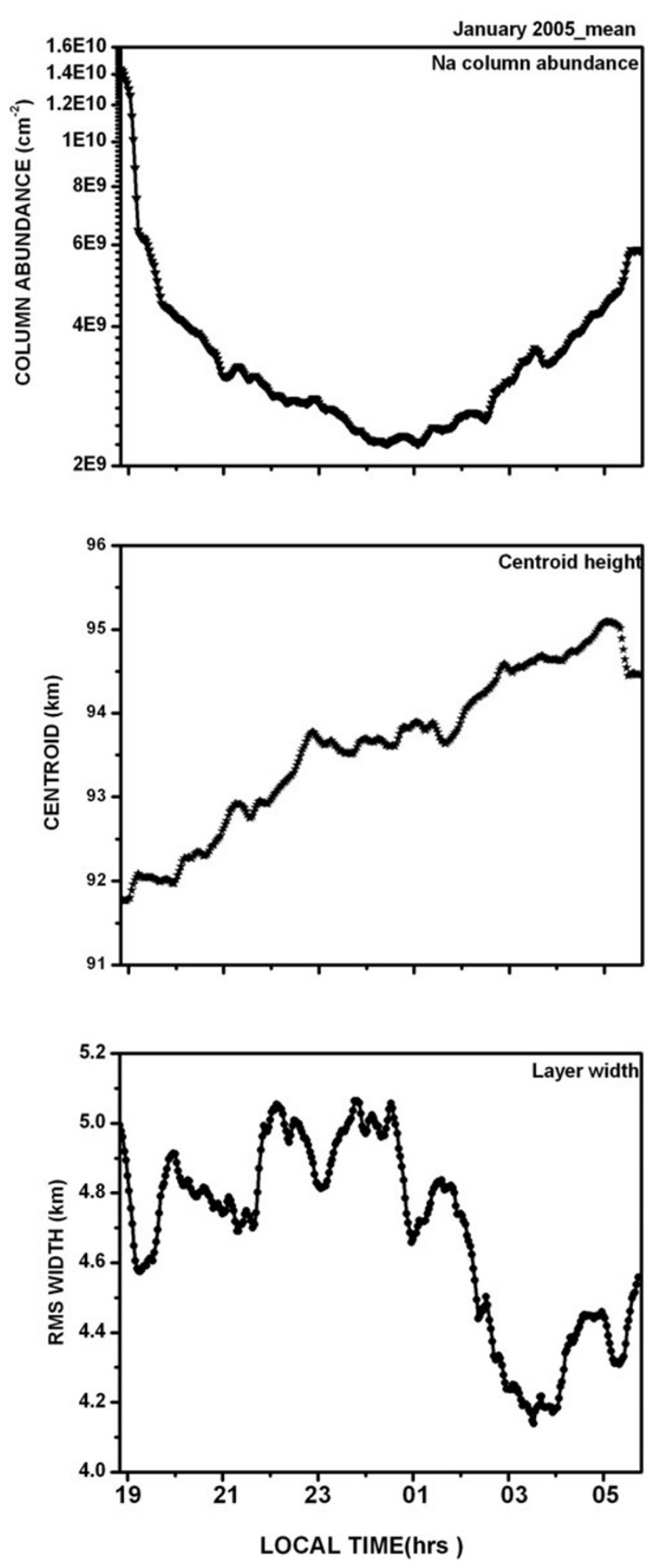

Fig. 6. Time evolution of Mean Na layer parameters derived from sodium measurements at Gadanki during January 2005. (a) Column abundance $\left(\mathrm{C}_{0}\right)$, (b) Centroid position $\left(\mathrm{z}_{0}\right)$, and (c) rms layer width $\left(\sigma_{0}\right)$.

depicts the temporal variation of $\mathrm{C}_{o}$ for January. The total $\mathrm{Na}$ content is found to vary between $2 \times 10^{9}$ and $8.9 \times 10^{9}$ atoms $\mathrm{cm}^{-2}$. It shows a variation of more than 400 percent. Simonich et al. (1979) found an average nocturnal variation by a factor of 2 in the sodium column abundance at $23^{\circ} \mathrm{S}$. Gardner et al. (1986) reported more than 200 percent variation in abundance over a midlatitude site. The best part of 
the lidar measurements at Gadanki site shows a steady fall in mean column abundance after sunset and a slow raise towards early hours of the day. This means that the total $\mathrm{Na}$ content decreases during the night and reaches minimum value during midnight and increases towards sunrise at early hours. The observed nighttime variation could be the manifestation of semidiurnal variation in the sodium layer. This could be perhaps the existence of solar-atmospheric tides in the layer. It is well known that atmospheric tides play an important role in the mesopause region (Chapman and Lindzen, 1970). A number of studies from a low latitude location (Clemesha et al., 1982; Batista et al., 1985; Clemesha et al., 2002) reported the presence of 12-hour oscillation in the sodium layer. Photochemistry in nighttime, dynamics or both may be responsible for the observed variations in the total $\mathrm{Na}$ content. Variations in the atomic oxygen number density could be the probable cause for such variations in the sodium content. However, dynamics associated with the layer through horizontal transport may also play a role in the observed variations. Batista et al. (1985) concluded that the semi-diurnal oscillations observed in the atmospheric sodium layer at $23^{\circ} \mathrm{S}$ were mainly induced by atmospheric tides. They were unable to identify any definite chemical effects responsible for such oscillations in the sodium layer. However, States and Gardner (1999) reported from midlatitudes that the variations observed in the sodium layer by them are forced by photochemical effects and not by tidal influenced. The detailed study of these oscillations, from the present data is restricted by the fact that sodium measurements with our lidar were obtained only during nighttime, for which the length of data possible is always less than 11 hours. Hence, it is too early for us to identify the cause for such observed variation in the total $\mathrm{Na}$ content. Figure $6(\mathrm{~b})$ presents the mean variation of the centroid $\left(\mathrm{z}_{o}\right)$ position of the layer for January. The movement of the sodium layer centroid is a very important parameter to consider for understanding the layer dynamics. The layer mean centroid position alters between 92.9 and $95.2 \mathrm{~km}$. The amplitude of the centroid movement is 2.3 $\mathrm{km}$ over the average period of measurement of the night in January. The average rate of variation is around $10 \mathrm{~cm} \mathrm{~s}^{-1}$, which is typical amplitude of semidiurnal wind reported in the layer (Batista et al., 1985). Figure 6(c) shows the mean variation of rms width of the layer $\left(\sigma_{o}\right)$ over the mean period for the six nights on which observations were made. The mean rms widths of the layer vary between 4.3 and $4.9 \mathrm{~km}$. The mean layer width has a peak-to-peak variation of about $600 \mathrm{~m}$. It appears that the layer width has an inphase relation with the sodium column abundance, but an anti-phase relation with the centroid height (Gardner et al., 1986). However, there is a significant wave nature appeared in mean layer width variation. Due to short and long period wave activity such as gravity waves and tides, the structure of the nocturnal layer changes substantially throughout the night. Variations of over 400 percent in abundance, more than $2 \mathrm{~km}$ in centroid height, and about $600 \mathrm{~m}$ in rms width have been observed within the time span of nocturnal observation.

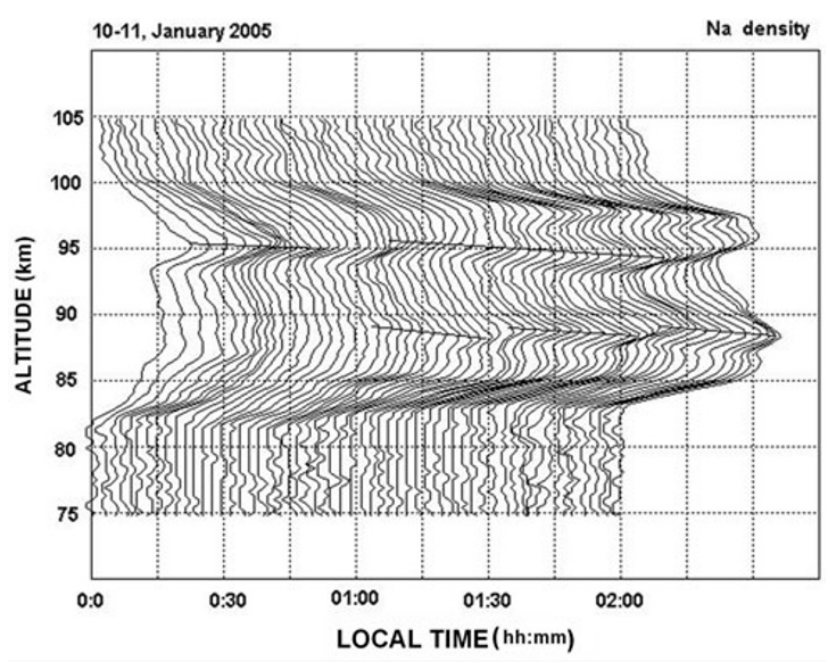

Fig. 7. Time series of sodium density profiles for 10 January 2005. Inclined lines represent apparent phase propagation.

\subsection{Wave parameters}

It is generally accepted that the mesospheric Na layer is an excellent tracer of the atmospheric wave motion. The distortions of meteor trails, variations in mesospheric density and temperature profiles, and the study of upper atmospheric disturbances led to the identification of atmospheric buoyancy waves or internal gravity waves (IGWs) as an important feature of dynamics in the upper mesosphere and lower thermosphere (Hines, 1974). These waves are referred to as internal gravity waves because the dominant restoring force on a displaced parcel of air is gravity and the vertical density gradient of the atmosphere allows them to propagate vertically through the medium. Distortions characteristic of the influence of IGWs on winds, density, and temperature give a reliable set of criteria from which to identify their presence. The observed features of meteor trail distortions outlined by Hines (1974) are specific to altitudes between 80 and $110 \mathrm{~km}$. A time series of 2-hour continuous observation of mesospheric $\mathrm{Na}$ layer on $10 \mathrm{Jan}-$ uary 2005 is shown in Fig. 7.

The time resolution of the measurement shown in Fig. 7 is $120 \mathrm{~s}$. The time evolution of perturbations of sodium layer due to gravity wave activity is evident. These perturbations are caused primarily by the vertical displacement of the layer due to vertical component of the gravity wave. Planetary and gravity waves generated in the troposphere propagate into the mesosphere, creating spatial modulations of sodium density profiles as well as temporal variations in sodium column density of the short time periods (Gardner and Shelton, 1985). To identify IGW signatures in the measured $\mathrm{Na}$ density, we subtracted the background density from each $\mathrm{Na}$ profile. It has been shown that a reasonably accurate model for the unperturbed Na layer (background density) is a Gaussian profile (Gardner and Voelz, 1987). Figure 8 shows the Na density perturbation profiles, which were obtained by background subtraction and normalization. The wave number, period, and amplitude of IGWs can be inferred from Na perturbation profiles (Gardner and Voelz, 1987). A simple Fourier transform of the 
Date : 10 January 2005

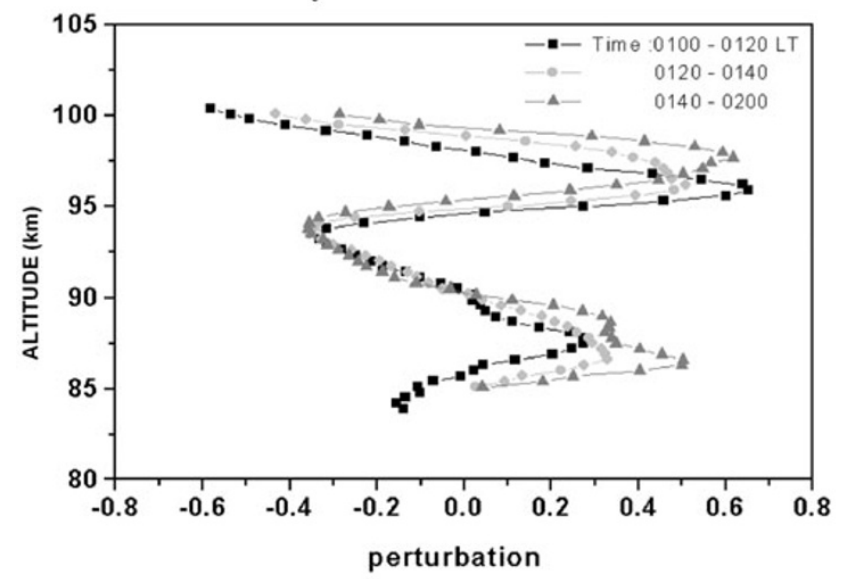

Fig. 8. Perturbation profiles derived from Na profiles for 10 January 2005 averaged for $20 \mathrm{~min}$. during the time interval between 0100 and 0200 LT.

perturbation produces a power spectrum that averaged over a time period. The power spectrum comprised of three terms: the first one indicates a low-frequency lobe in the spectrum. The second term represents the spectral signature of the interactive gravity wave, which is proportional to the square of the wave amplitude. This is shown as a local minimum between two peaks (Gardner and Voelz, 1987). The last term represents the second harmonic component of the gravity wave in action (i.e. generated due to non-linear interaction).

We have applied this analysis in a $20 \mathrm{~min}$. time window, between 0100 LT and 0200 LT, of the 10 January observations. The width of the Na layer sets the maximum vertical wavelength of the wave interacting with the Na layer. In the present study, the maximum vertical wavelength is about $15 \mathrm{~km}$. The altitude resolution decides the minimum wavelength detectable. In this study, the altitude resolution is $300 \mathrm{~m}$. The calculated mean power spectrum is shown in Fig. 9. The feature of the principal wave interacting with the Na layer is evident as the local minimum between the first two peaks on the side of the low frequency part of the spectrum, which indicates the characteristic vertical gravity wave number $\left(\mathrm{m}_{o}=0.31 \mathrm{~km}^{-1}\right)$. This corresponds to approximately $3.2 \mathrm{~km}$ wavelength. This wavelength is characteristic wavelength $\left(\lambda_{o}=2 \pi / \mathrm{m}_{o}\right)$. The other notch between weaker peaks is at about twice the value of the interactive gravity wave number, which corresponds to 0.62 $\mathrm{km}^{-1}$, generated due to non-linear process. The observations of vertical wavelengths of order $3 \mathrm{~km}$ have been observed using lidars, radars and rockets at the mesopause region (Blood et al., 1988; Williams et al., 2006). Usually long period waves such as tides are associated with shorter wavelengths (Williams et al., 2006). The phase velocity of the wave is estimated by dividing the vertical distance the individual wave fronts travel by time between successive observations. The vertical velocity of the wave can be estimated by looking at the motion of the successive peaks, as shown by the inclined lines in Fig. 7. The apparent phase velocity is about $1.0 \mathrm{~km} \mathrm{~h}^{-1}$ or $30 \mathrm{~cm} \mathrm{~s}^{-1}$, which is consistent with the reported values of the semidiurnal tide in $\mathrm{Na}$

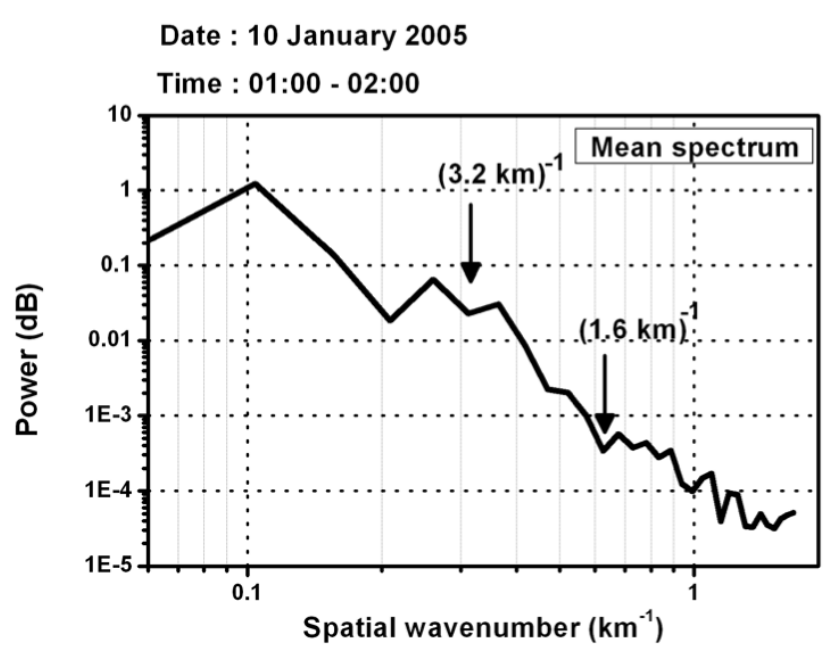

Fig. 9. Power spectrum for the perturbation profiles shown in Fig. 8. layer (Simonich et al., 1979; Kwon et al., 1987).

\subsection{Observation of Sporadic Na layer}

An interesting and current topic of interest with the mesospheric Na layer is the sporadic occurrence of thin layers of enhanced number density superposed on the regular background layer. These sporadic layers generate sharp sodium abundance peaks of full width at half maximum (FWHM) typically between several hundred meters and less than a few $\mathrm{km}$ thick with number density equal to or greater than twice that of the background $\mathrm{Na}$ layer. These layers persist for periods a few minutes to several hours. These sporadic layers appear to be related to the ion layers known as sporadic $\mathrm{E}$, or Es, and for this reason are sometimes referred to as $\mathrm{Na}_{s}$ layers. We have followed the objective method and the criteria given by Miyagawa et al. (1999) for identification of $\mathrm{Na}_{s}$ layers in the mesospheric $\mathrm{Na}$ layer. Accordingly, in the initial 6 nights of observation, during 54 hours of Na measurements, a total of $4 \mathrm{Na}_{s}$ layers were observed. The statistical details of the observed Nas layers are listed in Table 3.

On the night of January 10, a sporadic layer was seen between 2200 and 0000 LT and was persisted for about an hour. The altitude of peak number density of the layer was seen at $96.4 \mathrm{~km}$ with a strength factor of about 4.5 . von Zahn and Hansen (1988) defined a parameter called strength factor to classify the intensity of the sporadic layer. It is the ratio of maximum peak number density of the sporadic layer to the number density of the normal layer at the altitude of the peak of the sporadic layer. Figure 10 shows the altitude/temporal variation of the Na layer during the night of January 11, 2005. On this night, a regular Na layer was seen at the beginning of the experiment as a broad layer extended from 80 to $100 \mathrm{~km}$. At $0232 \mathrm{LT}$ a sporadic layer was formed at about $93 \mathrm{~km}$. Subsequently this sporadic Na layer was observed continuously for almost 2 hours till early morning hours. The peak number density of the sporadic sodium layer is plotted versus time in Fig. 11. The peak of $\mathrm{Na}$ layer moved downward from about $96 \mathrm{~km}$ to $90 \mathrm{~km}$, with a constant velocity of $24 \mathrm{~cm} \mathrm{~s}^{-1}$. The altitude of this layer is plotted versus time in Fig. 12. 
Table 3. Details of sporadic sodium layer observation.

\begin{tabular}{cccccccc}
\hline Sl.no & $\begin{array}{c}\text { Night observation } \\
\text { in January 2005 }\end{array}$ & $\begin{array}{c}\text { Period of } \mathrm{Na}_{s} \text { layer } \\
\text { Observation (LT) }\end{array}$ & $\begin{array}{c}\text { Duration Of } \\
\text { SSL (hh:mm) }\end{array}$ & $\begin{array}{c}\text { Time of Max. } \\
\text { Density (LT) }\end{array}$ & $\begin{array}{c}\text { Alt. of Max. } \\
\text { Density (km) }\end{array}$ & $\begin{array}{c}\text { FWHM (km) } \\
\text { Max.peak } \\
\text { Density (cm }{ }^{-3} \text { ) }\end{array}$ & $\begin{array}{c}\text { Strength } \\
\text { factor }\end{array}$ \\
\hline 1 & $10-11$ & $22.21-23.38$ & 01.17 & 22.35 & 96.77 & 2.1 & 10296 \\
2 & $11-12$ & $02.32-04.32$ & 02.00 & 03.39 & 91.68 & 1.5 & 29909 \\
3 & $15-16$ & $21.15-22.24$ & 01.09 & 22.00 & 95.28 & 1.0 & 14447 \\
4 & $16-17$ & $21.16-00.37$ & 03.21 & 23.40 & 95.87 & 3.0 & 4466 \\
\hline
\end{tabular}

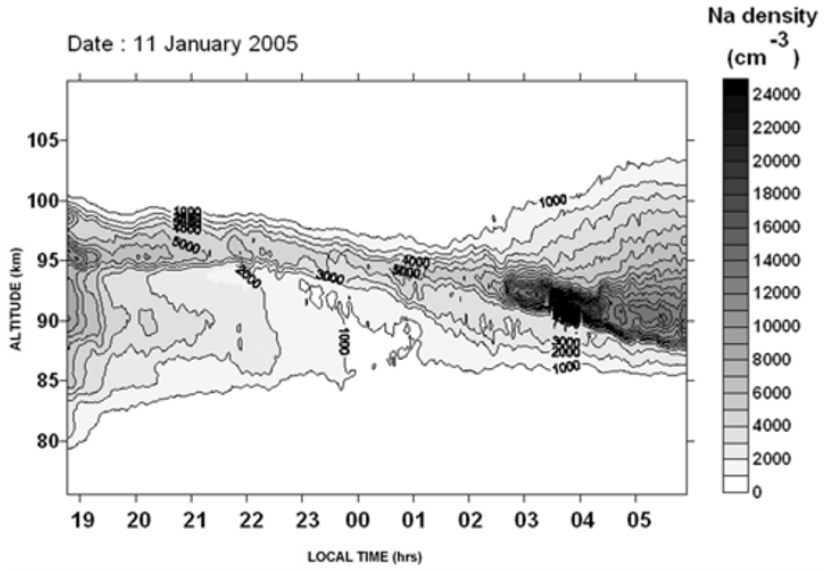

Fig. 10. Altitude/Temporal variation of Na density observed on the night of 11 January 2005.

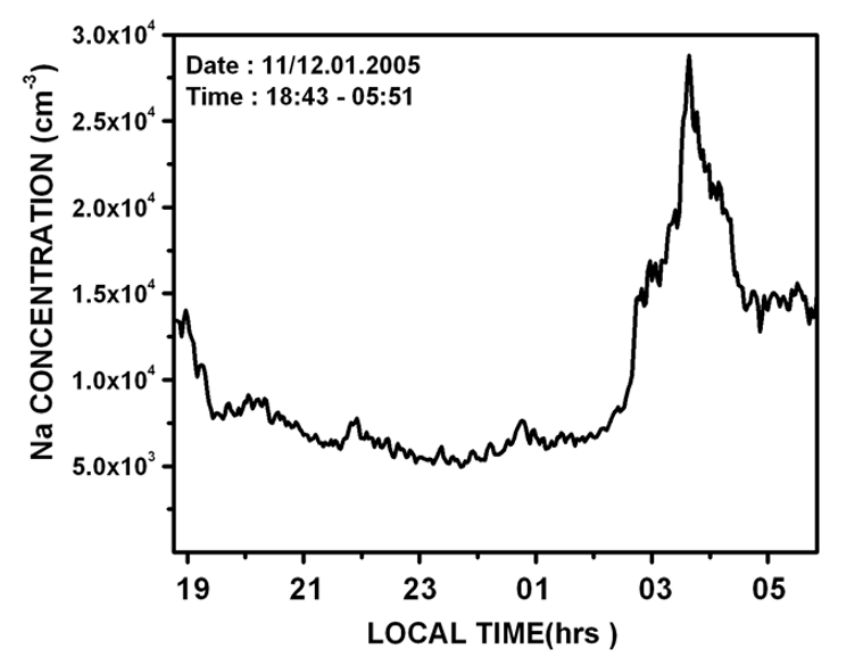

Fig. 11. Temporal variation of the density at the peak of the dominant sporadic Na layer observed on the night of January 11, 2005, at Gadanki site.

When the layer descended to an altitude of $91.6 \mathrm{~km}$ at $0345 \mathrm{LT}$, the peak number density reached a maximum of about $29,900 \mathrm{~cm}^{-3}$. In the entire measurement period, the observed $\mathrm{Na}_{s}$ layer has the remarkable peak sodium distribution. Figure 13 shows the peak sporadic sodium layer occurrence on the background $\mathrm{Na}$ layer observed on the night of 11 January, 2005 at 0339 LT. On the night of January 15, a strong sporadic layer occurrence at $95 \mathrm{~km}$ altitude was observed between 2100 and 2300 LT with a strength factor of about 12 and was observed for about one

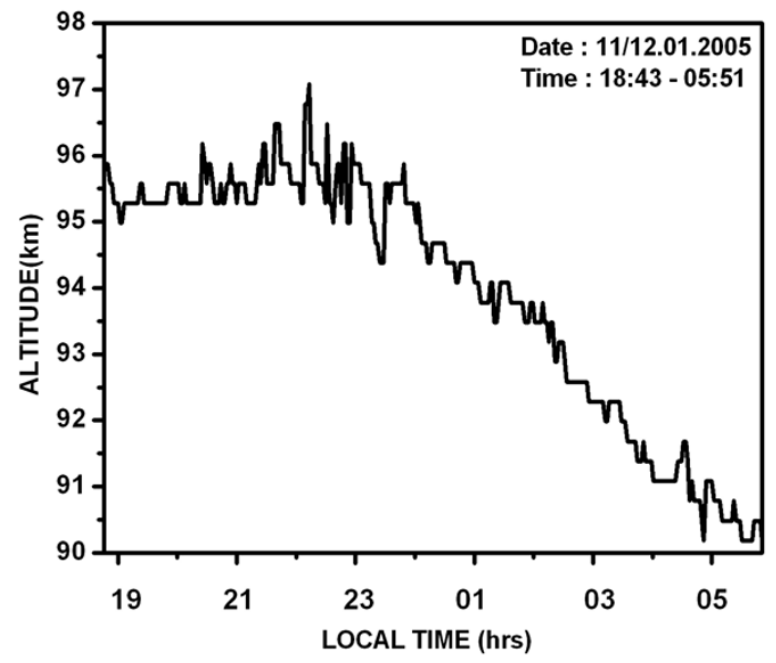

Fig. 12. Temporal variation of the altitude of the dominant sporadic $\mathrm{Na}$ layer observed on the night of January 11, 2005, at Gadanki site.

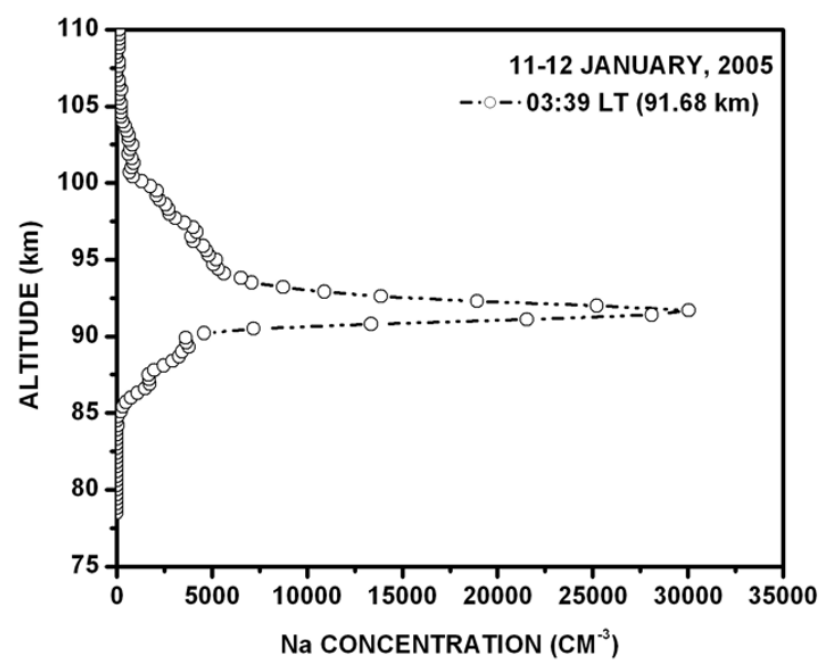

Fig. 13. Peak sporadic layer formation on the background $\mathrm{Na}$ layer observed on the night of 11 January, 2005 at 0339 LT.

hour time period.

The peak number density of the sporadic sodium layer is plotted versus time in Fig. 14. Figure 14 shows a narrow and concentrated sodium distribution in to a layer of a few hundred meters thick. On the night of January 16, a relatively long-lived sporadic layer was observed at an altitude of about $96 \mathrm{~km}$. The layer was observed between 2100 and 0100 LT for about 3 hours. The strength factor of the layer was about 6 . 
Table 4. Details of meteor induced enhanced sodium observation.

\begin{tabular}{cccccccc}
\hline Sl.no & $\begin{array}{c}\text { Night observation } \\
\text { in January 2005 }\end{array}$ & $\begin{array}{c}\text { Period of enhanced } \\
\text { Na layer observation (LT) }\end{array}$ & $\begin{array}{c}\text { Duration } \\
(\text { hh.mm) }\end{array}$ & $\begin{array}{c}\text { Time of Max } \\
\text { Density (LT) }\end{array}$ & $\begin{array}{c}\text { Alt. of Max. } \\
\text { Density(km) }\end{array}$ & $\begin{array}{c}\text { FWHM (km) } \\
\text { Max peak } \\
\left.\text { Density (cm }{ }^{-3}\right)\end{array}$ & $\begin{array}{c}\text { Density } \\
\text { ratio }\end{array}$ \\
\hline 1 & $12-13$ & $02.34-02.38$ & 00.04 & 02.38 & 95.87 & 2.50 & 2680 \\
2 & $12-13$ & $03.34-03.38$ & 00.04 & 03.38 & 95.58 & 2.75 & 2641 \\
3 & $12-13$ & $04.05-04.09$ & 00.04 & 04.09 & 94.98 & 2.75 & 2606 \\
4 & $12-13$ & $04.49-04.55$ & 00.06 & 04.51 & 93.78 & 3.00 & 2469 \\
\hline
\end{tabular}

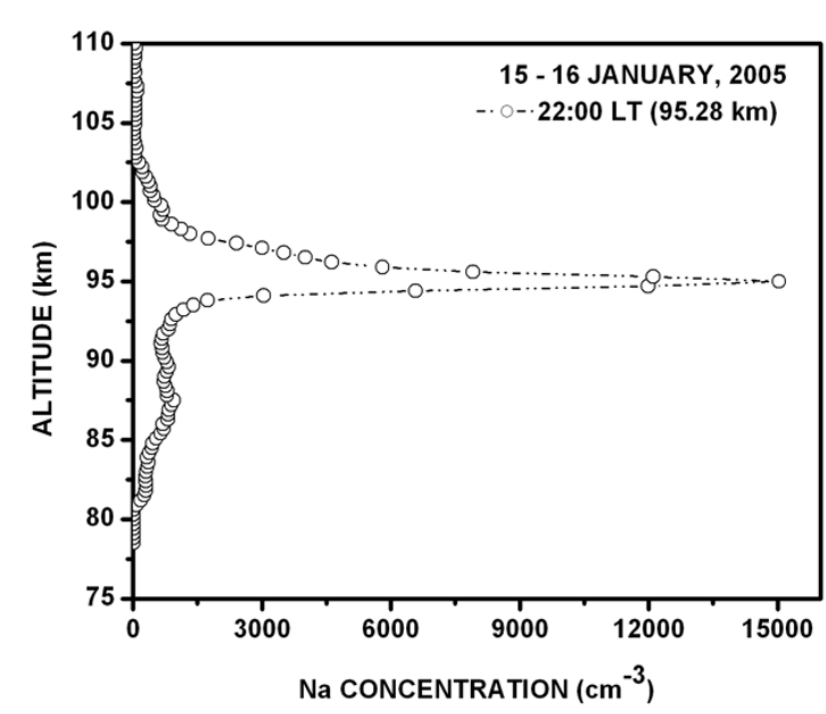

Fig. 14. A narrow sporadic layer formation on the background $\mathrm{Na}$ layer observed on the night of 15 January, 2005 at 2200 LT.

Lidar observations at low latitudes indicated that the occurrences of sporadic $\mathrm{Na}$ layers were usually in the upper part of the normal sodium layers and they often showed a downward motion with time (Batista et al., 1991). Dynamical effects associated with tides, gravity waves and turbulence may also contribute to the formation of sporadic $\mathrm{Na}$ layers (Clemesha et al., 1988; Zhou and Mathews, 1995). The sporadic layers in mesospheric Na have been observed at other locations, but their occurrence characteristics seem to vary significantly between the places. Kwon et al. (1988) reported at Mauna Kea $\left(20^{\circ} \mathrm{N}\right)$ that $16 \mathrm{Na}_{s}$ layers were seen in $30 \mathrm{~h}$ of observations. However, Clemesha et al. (1998) observed only 1 layer in $27 \mathrm{~h}$ measurements at Alcantara $\left(2^{\circ} \mathrm{S}\right)$. The reported observations suggest that the occurrence frequency of $\mathrm{Na}_{s}$ layers decreases as we move from the northern hemisphere low-latitudes towards the southern hemisphere low latitudes. Our observations seem to support the above conclusion, because the observed $8 \mathrm{Na}_{s}$ layers during nearly $54 \mathrm{~h}$ of measurements at Gadanki $\left(13.5^{\circ} \mathrm{N}\right)$ fall between the reported observations at Mauna Kea $\left(20^{\circ} \mathrm{N}\right)$ and Alcantara $\left(2^{\circ} \mathrm{S}\right)$. However, recently Nagasawa and Abo (1995) suggested that the occurrence rate of Nas layers at any location might be related to its magnetic rather than to geographic latitude. Studies on sporadic Na layers have also shown that there is considerable experimental correlation for the occurrences of the mesospheric sporadic $\mathrm{Na}$ and sporadic E layers (von Zahn and Hansen, 1988; Cox and Plane, 1998; Clemesha et al., 1999). It is suggested that the

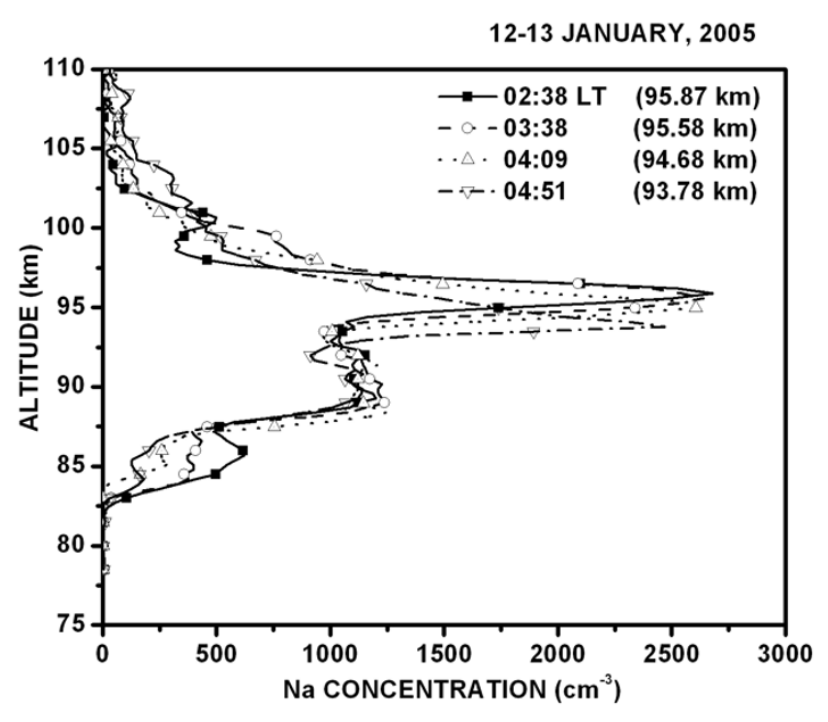

Fig. 15. Observation of narrow sodium layer formations on the night of 12-13 January 2005 due to meteorite ablation.

neutralization of the $\mathrm{Na}$ ion reservoir in the Es layers is the source of the neutral $\mathrm{Na}$ atoms. However, the origin of sporadic sodium layers is still uncertain and involves a more dynamical process (Clemesha, 1995).

\subsection{Observation of meteoric induced enhanced $\mathrm{Na}$ layer}

It is generally believed that the ablation of meteoroids is the only source of metal atoms at the mesopause altitude region. The invention of resonance lidars has made it possible to measure the densities of different metal atoms quantitatively with high vertical and temporal resolution, even inside the trail of an individual meteoroid (Kane and Gardner, 1993; Grime et al., 1999; von Zahn et al., 1999; Drummond et al., 2001, 2002). In our observations, on the night of January 12, four narrow layers of atomic sodium enhancement observed with in a time interval of 3 hours, between 0200 and 0500 LT, as shown in Fig. 15. These layers strength factors appeared in the range between 2 and 3 . However, short lifetime, about 4 to 6 minute, is found as the characteristic of these layers. The altitudes of peak number density are appeared between 93 and $96 \mathrm{~km}$. The observational details of the enhanced Na layers are listed in Table 4. We understood that the formation of these narrow layers in short period, such as a few seconds to a few minutes, probably due to advection of meteor trails across the lidar field of view (FOV). In particular, observations during meteor showers such as the prominent Leonids have widely been used to demonstrate the influence of single meteors on the 
local metal layer (Hoffner et al., 1999, 2000; Kruschwitz et al., 2001). From such experiments it has become clear that single meteoroids can, in many instances, have large impacts for a short period on the local metal layers.

\section{Conclusion}

The first broadband resonance lidar observations of the nighttime sodium layer made on six nights between 10 and 16 January 2005 at Gadanki, a low latitude site, in India have been reported in this paper. During the 6 nights of the initial observational period, nearly 54 hours of Na measurements were obtained. The sodium profile starts to appear around $80 \mathrm{~km}$ and rises to a peak close to $95 \mathrm{~km}$ and then falls to near zero around $105 \mathrm{~km}$. The topside scale height is always less than $2 \mathrm{~km}$. On three occasions out of a total of six nights of measurements a secondary peak in sodium number density was observed at heights between 87 and $92 \mathrm{~km}$. The mean sodium column abundances were in the range of $2-8.9 \times 10^{9} \mathrm{~cm}^{-2}$. The measurements also show the effects of strong tidal perturbations, presumably with a dominant downward propagating semidiurnal tide, but the detailed analysis is not possible due to limited local time coverage. We have seen wave like structures in the sodium layer with typical wavelength of $3.1 \mathrm{~km}$ and with downward phase velocities of about $1 \mathrm{~km} \mathrm{~h}^{-1}$. We have also seen the occurrence of sporadic Na layer over the background mesospheric sodium. A total of 4 sporadic layers were observed during the $54 \mathrm{~h}$ of measurement period. Formation and decay of a sporadic layer observed on the night of January 11, 2005 , which persisted for a period of about 2 hours, was discussed. The formation of sporadic Na layer developed during downward motion of mesospheric Na layer. Our observations of sporadic Na layer are similar to that reported over other low latitudes. Meteorite induced $\mathrm{Na}$ enhancement, which was observed on 12 January 2005, was also discussed.

\section{Future plans}

The paper presents the first results from the broadband $\mathrm{Na}$ lidar setup at NARL, Gadanki, India. The system has successfully demonstrated the capability to detect waves and other dynamical phenomena such as sporadic layers in the mesopause region. At present, the lidar system configuration allows laser operation in resonant scatter mode only, due to constraints in the laser power distribution. In future, it is planned to operate both the Rayleigh and resonance modes simultaneously. This augmentation helps to understand the wave dynamics in the nocturnal atmosphere covering 30 to $105 \mathrm{~km}$ altitude range. Moreover, the extension of $\mathrm{Na}$ lidar operation to daytime enables the study of tides in the mesopause region. By narrowing the linewidth of laser, it is also possible to scan the $\mathrm{Na}_{2}$ spectrum, from which mesospheric temperatures can be obtained.

Acknowledgments. One of the authors, Y. Bhavani Kumar, would like to thank the NARL, Department of Space, Government of India for funding the project "Sodium lidar" and also providing necessary infrastructural support extended to realize the project in to regular operational mode.

\section{References}

Alpers, M., T. Blix, S. Kirkwood, D. Krankowsky, F. J. Lubken, L. Lutz, and U. von Zahn, First simultaneous measurements of neutral and ionized iron densities in the upper mesosphere, J. Geophys. Res., 98, 275283, 1993.

Batista, P. P., B. R. Clemesha, D. M. Simonich, and V. W. J. H. Kirchhoff, Tidal oscillations in the atmospheric sodium layer, J. Geophys. Res., 90, 3881-3888, 1985.

Batista, P. P., B. R. Clemesha, and D. M. Simonich, Horizontal structures in sporadic sodium layers at $23^{\circ} \mathrm{S}$, Geophys. Res. Lett., 18, 1027-1030, 1991.

Beatty, T. J., R. L. Collins, C. S. Gardner, C. A. Hostetler, and C. F. Sechrist Jr., Simultaneous radar and lidar observations of sporadic $\mathrm{E}$ and $\mathrm{Na}$ layers at Arecibo, Geophys. Res. Lett., 16, 1019-1022, 1989.

Bhavani Kumar, Y., V. Siva Kumar, P. B. Rao, M. Krishnaiah, K. Mizutani, T. Aoki, M. Yasui, and T. Itabe, Middle atmospheric temperature measurements using ground based instrument at a low latitude, Ind. J. Rad. and Space Phys., 29, 249-257, 2000.

Bhavani Kumar,Y., V. Siva Kumar, A. R. Jain, and P. B. Rao, MST Radar and Polarization lidar observations of tropical cirrus, Annales Geo. Phy., 19, 873-883, 2001.

Bhavani Kumar, Y., C. Nageswara Raju, and M. Krishnaiah, Indo-Japanese Lidar observations of the Tropical Middle Atmosphere during 1998 and 1999, Adv. Atm, Sci., 23, 711-725, 2006.

Bhavani Kumar, Y., D. Narayana Rao, M. Sundaramurthy, and M. Krishnaiah, A resonance lidar system for mesospheric sodium measurements, Journal of Optical Engineering, 2007 (in press).

Bills, R. E. and C. S. Gardner, Lidar observations of mesospheric Fe and sporadic Fe layers at Urbana, Illinois, Geophy. Res. Lett., 17, 143-146, 1990.

Blood, S. P., J. D. Mitchell, C. L. Croskey, T. D. Raymund, E. V. Thrane, T. A. Blux, U. P. Hoppe, D. C. Fritts, and F. J. Scmidlin, Studies of high latitude mesospheric turbulence by radar and rocket II: Measurements of small scale turbulence, J. Atmos. Terr. Pys., 50, 963-976, 1988.

Chapman, S. and R. S. Lindzen, Atmospheric tides, 200 pp, D. Reidel Press, Dordrecht, Holland, 1970.

Clemesha, B. R., Sporadic neutral metal layers in the mesosphere and lower thermosphere-Review paper, J. Atmos. Terr. Phys., 57, 725-736, 1995

Clemesha, B. R., V. W. J. H. Kirchhoff, D. M. Simonich, and H. Takahashi, Evidence of an extraterrestrial Source for the Mesospheric Sodium Layer, Geophys. Res. Lett., 5, 873-876, 1978.

Clemesha, B. R., D. M. Simonich, P. P. Batista, and V. W. J. H. Kirchhoff, The diurnal variation of atmospheric sodium, J. Geophys. Res., 87, 181186, 1982.

Clemesha, B. R., P. P. Batista, and D. M. Simonich, Concerning of the origin of enhanced sodium layers, Geophys. Res. Lett., 16, 1267-1270, 1988.

Clemesha, B. R., D. M. Simonich, P. P. Batista, and H. Takahashi, Evidence for a lack of diffusive control of the atmospheric sodium layer, J. Atmos. Terr. Phys., 54, 355-362, 1992.

Clemesha, B. R., D. M. Simonich, H. Takahasi, S. M. L. Melo, and J. M. C. Plane, Experimental evidence for photochemical control of the atmospheric sodium layer, J. Geophy. Res., 100, 18,909-18,916, 1995.

Clemesha, B. R., D. M. Simonich, P. P. Batista, and I. S. Batista, Lidar observation of atmospheric sodium at an equatorial location, J. Atmos. Terr. Phys., 60, 1773-1778, 1998.

Clemesha, B. R., P. P. Batista, and D. M. Simonich, An evaluation of the evidence for ion recombination as a source of sporadic neutral layers in the lower thermosphere, Adv. Space Res., 23, 547-556, 1999.

Clemesha, B. R., P. P. Batista, and D. M. Simonich, Simultaneous measurements of meteor winds and sporadic sodium layers in the 80-110 km region, Adv. Space. Res., 27, 1679-1684, 2001.

Clemesha, B. R., P. P. Batista, and D. M. Simonich, Long-term variations in the centroid height of the atmospheric sodium layer, 34th scientific assembly of COSPAR, Houston, Texas, USA, 10-19 October, 2002.

Cox, R. M. and J. M. C. Plane, An ion-molecule mechanism for the formation of neutral sporadic Na layers, J. Geophys. Res., 103, 63496359, 1998.

Drummond, J. D., B. W. Grime, C. S. Gardner, A. Z. Liu, X. Chu, and T. J. Kane, Observations of persistent Leonid meteor trails: 1. Advection of the "Diamond Ring", J. Geophys. Res., 106, 21517-21524, 2001.

Drummond, J. D., B. W. Grime, C. S. Gardner, A. Z. Liu, X. Chu, M. C. Kelley, C. Kruschwitz, and T. J. Kane, Observations of persistent Leonid meteor trails 3. The "Glowworm", J. Geophys. Res., 107, SIA 
5-1, doi:10.1029/2001JA000223, 2002.

Fricke, K. H. and U. von Zahn, Mesopause temperatures derived from probing the hyperfine structure of the $\mathrm{D}_{2}$ resonance line of sodium by lidar, J. Atmos. Terr. Phys., 47, 499-512, 1985.

Gardner, C. S., Sodium resonance fluorescence lidar applications in atmospheric science and astronomy, IEEEP, 77, 408-418, 1989.

Gardner, C. S. and J. D. Shelton, Density response of neutral atmospheric layers to gravity wave perturbations, J. Geophys. Res., 90, 1745-1754, 1985.

Gardner, C. S. and D. G. Voelz, Lidar studies of the nighttime sodium layer over Urbana, Illinois 2. Gravity waves, J. Geophys. Res., 92, 4673-4694, 1987.

Gardner, C. S., D. G. Voelz, C. F. Sechrist Jr., and A. C. Segal, Lidar studies of the nighttime sodium layer over Urbana, Illinois, 1. Seasonal and nocturnal variations, J. Geophys. Res., 91, 13659-13673, 1986.

Gardner, C. S., D. C. Senft, T. J. Beatty, R. E. Bills, and C. A. Hosteller, Rayleigh and sodium lidar techniques for measuring the middle atmosphere density, temperature and wind perturbations and their spectra, WITS Handbook, 2, 148-1187, 1989.

Geisler, J. E. and R. E. Dickinson, Comment on "Upper atmosphere sodium and stratospheric warmings at high latitudes", J. Atmos. Sci., 24, 720-721,1967.

Granier, C., J. P. Jegou, and G. Megie, Resonant lidar detection of Ca and $\mathrm{Ca}+$ in the upper atmosphere, Geophy. Res. Lett., 12, 655-658, 1985.

Grime, B. W., T. J. Kane, S. C. Collins, M. C. Kelley, C. A. Kruschwitz, J. S. Friedman, and C. A. Tepley, Meteor trail advection and dispersion: Preliminary lidar observations, Geophys. Res. Lett., 26, 675-678, 1999.

Hanson, W. B. and J. S. Donaldson, Sodium distribution in the upper atmosphere, J. Geophys. Res., 72, 5513-5514, 1967.

Hines, C. O., Dynamical heating of the upper atmosphere, J. Geophys. Res., 70, 177, 1974.

Hoffner, J., U. von Zahn, W. J. McNeil, and E. Murad, The 1996 Leonid shower as studied with a potassium lidar: Observations and inferred meteoroid sizes, J. Geophys. Res., 104, 2633-2643, 1999.

Hoffner, J., C. Fricke-Begemann, and U. von Zahn, Note on the reaction of the upper atmosphere potassium layer to the 1999 leonid meteor storm, Earth, Moon and Planets, 82-83, 555-564, 2000.

Hunten, D. M., A meteor-ablation model of the sodium and potassium layers, Geophys. Res. Lett., 8, 369-372, 1981.

Kane, T. J. and C. S. Gardner, Lidar observations of meteoric deposition of mesospheric metals, Science, 259, 1297-1300, 1993.

Kane, T. J., C. S. Gardner, Q. Zhou, J. D. Mathews, and C. A. Tepley, Lidar, radar and airglow observations of a prominent sporadic $\mathrm{Na} /$ Sporadic $\mathrm{E}$ layer event at Arecibo during AIDA-89, J. Atmos. Terr. Phys., 55, 499$511,1993$.

Kane, T., B. Grime, S. Franke, E. Kudeki, E. Urbina, M. Kelley, and S. Collins, Joint Observations of Sodium Enhancements and Field-Aligned Ionospheric irregularities, Geophys. Res. Lett., 28, 1375-1378, 2001.

Kirchhoff, V. W. J. H. and B. R. Clemesha, Atmospheric sodium measurements at $23^{\circ}$ S, J. Atmos. Terr. Phys., 35, 1493-1498, 1973.

Kirchhoff, V. W. J. H., B. R. Clemesha, and D. M. Simonich, The atmospheric neutral sodium layer, 1 . Recent modeling compared to measurements, J. Geophys. Res., 66, 6892-6898, 1981.

Kruschwitz, C. A., M. C. Kelley, C. S. Gardner, G. Swenson, A. Z. Liu, X. Chu, J. D. Drummond, B. W. Grime, W. T. Armstrong, J. M. C. Plane, and P. Jenniskens, Observations of persistent Leonid meteor trails, 2. Photometry and numerical modelling, J. Geophys. Res., 106, 21 525, (2000JA000174), 2001

Kwon, K. H., C. S. Gardner, D. C. Senft, F. L. Roesler, and J. Harlander, Daytime lidar measurements of tidal winds in the mesospheric sodium layer at Urbana, Illinois, J. Geophys. Res., 92, 8781-8786, 1987.

Kwon, K. H., D. C. Senft, and C. S. Gardner, Lidar observations of spo- radic sodium layers at Mauna Kea Observatory, Hawaii, J. Geophys. Res., 93, 14199-14208, 1988.

Miyagawa, H., T. Nakamura, T. Tsuda, M. Abo, C. Nagasawa, T. D. Kawahara, K. Kobayashi, T. Kitahara, and A. Nomura, Observations of mesospheric sporadic sodium layers with the MU radar and sodium lidars, Earth Planets Space, 51, 785-797, 1999.

Nagasawa, C. and M. Abo, Lidar observations of a lot of sporadic sodium layer in mid-latitude, Geophys. Res. Lett., 22, 263-266, 1995.

Nicolet, M., On the molecular scattering in the terrestrial atmosphere: An empirical formula for its calculation in the homosphere, Planet. Space Sci., 32, 1467-1468, 1984.

Plane, J. M. C., The chemistry of meteoric metals in the Earth's upper atmosphere, Int. Rev. Phys. Chem., 10, 55, 1991.

Richter, E. S. and C. F. Sechrist Jr, A cluster ion chemistry for the mesospheric sodium layer, J. Atmos. Terr. Phys., 41, 579-586, 1979.

Richter, E. S., J. R. Rowlett, C. S. Gardner, and C. F. Sechrist Jr., Lidar observation of the mesospheric Na layer over Urbana, Illinois, J. Atmos. Terr. Phys., 43, 327-337, 1981.

Shibata, Y., C. Nagasawa, M. Abo, T. Maruyama, S. Saito, and T. Nakamura, Lidar observations of sporadic $\mathrm{Fe}$ and Na layers in the mesopause region over Equator, J. Met. Soc. of Japan, 84A, 317-325, 2006.

Simonich, D. M., B. R. Clemesha, and V. W. J. H. Kirchhoff, The mesospheric sodium layer at $23^{\circ} \mathrm{S}$ : Nocturnal and seasonal variations, J. Geophys. Res., 84, 1543-1550, 1979.

Simonich, D. M. and B. R. Clemesha, Resonant extinction of lidar from the alkali metal layers in the upper atmosphere, Appl. Optics, 22, 13871389, 1983.

Slipher, V. M., Emission in the spectrum of the light of the night sky, Publ. Astron. Soc. Pac., 41, 262-263, 1929.

States, R. J. and C. S. Gardner, Structure of the mesospheric Na layer at $40^{\circ} \mathrm{N}$ latitude: seasonal and diurnal variations, J. Geophys. Res., 104, 11783-11798, 1999

von Zahn, U. and T. L. Hansen, Sudden neutral sodium layers: A strong link to sporadic E layers, J. Atmos. Terr. Phys., 50, 93-104, 1988.

von Zahn, U., M. Gerding, J. Hoffner, W. J. McNeil, and E. Murad, Fe, Ca, and $\mathrm{K}$ atom densities in the trails of Leonids and other meteors: Strong evidence for differential ablation, Meteorit. Planet. Sci., 34, 1017-1027, 1999.

Williams, B. P., D. C. Fritts, J. D. Vance, C. Y. She, T. Abe, and E. Thrane, Sodium lidar measurements of waves and instabilities near the mesopause region during the DELTA rocket campaign, Earth Planets Space, 58, 1131-1137, 2006

Williams, B. P., D. C. Fritts, C. Y. She, and R. A. Goldberg, Gravity wave propagation through a large semidiurnal tide and instabilities in the mesosphere and lower thermosphere during the winter $2003 \mathrm{MaCWAVE}$ rocket campaign, Ann. Geophys., 24, 1199-1208, 2006.

Xu, J. and A. K. Smith, Perturbations of the sodium layer controlled by chemistry or dynamics, Geophys. Res. Lett., 30(20), 2056-2059, 2003.

Xu, J., A. K. Smith, and R. A. Ma, Numerical study of the effect of gravity wave propagation on minor species distribution in the mesopause region, J. Geophys. Res., 108, 10.10291/2001JD001570, 2003.

Yi, F., S. Zhang, H. Zeng, Y. He, X. Yue, J. Liu, H. Lv, and D. Xiong, Lidar observations of sporadic Na layers over Wuhan $\left(30.5^{\circ} \mathrm{N}, 114.4^{\circ} \mathrm{E}\right)$, Geophys. Res. Lett., 29, 59.1-59.4, 2002.

Zhou, Q. and J. D. Mathews, Generation of sporadic sodium layers via turbulent heating of the atmosphere, J. Atmos. Terr. Phys., 57, 13091320, 1995.

Y. B. Kumar (e-mail: ypbk@narl.gov.in), P. V. Prasanth, D. N. Rao, M. S. Murthy, and M. Krishnaiah 